express the complete solution of the problem. Whatever formula should be adopted, as Prof. Unwin remarks, a table based upon it for practical use will divest the source of the table from any inconvenience, and possess the merit of correctness not belonging to an erroneous though simple rule.

Unfortunately, Fairbairn's experiments refer to a tube whose failure can only occur by passing the limits of crushing strength (which Prof. Unwin properly states, for wrought iron, to be 80 or even 100 tons per square inch), or by want of uniformity of the material; and his results are finally based on the average imperfection of his tubes in this last particular. While the requirement of the engineer is to know what are the limits of strength of flues made from plates riveted up, and subjected at once to the strains of their setting in the boiler, and to external pressure. Further experiments are clearly desirable, in place of arguing as to the construction of Fairbairn's formula with reference to its misapplication to boiler flues.

\title{
THE MANUFACTURE OF STEEL AND MODE OF WORKING IT.
}

By D. Chernorf, Assistant Manager of the Abouchoff Cast Steel Works, near St. Petersburg. Translated by W. Anderson, M. Inst. C.E.

Communication to the Ressian Techncal Socretr, 1868.

[From The Engineer, July ith, 18:6.]

Steel, as generally used in the arts, is a combination of iron and carbon. The purer these elements in steel, the higher are its qualities. The best steel that has ever been made in any age or country is, without question, "boulat" (the sabre steel of the Tartars). The special qualities of boulat, and especially the markings appearing on its surface, have sent many investigators on a wrong scent; all thought to find the extraordinary qualities of this steel in some special mixture. Careful analyses have been made, but, to the surprise of all, nothing has been found competent to explain the presence of the characteristic veining. Inasmuch as the veining of boulat is closely connected with its quality, it was attempted to find substances which, being melted with the steel, would produce the markings required. Steel was melted with various metals, with platinum, silver,

Whole No. Vol. CII.-(Thrrd Breme, Vol. Ixrii.) 
and so on, and veinings were, no doubt, produced; but in the first place, they were far from having the same regularity and beauty, and secondly, as well as chiefly, the steel produced was always inferior to boulat. The peculiarity of the veining of boulat lies also in this, that if you heat a good specimen of the steel with clearly marked veining to a bright red heat, and then allow it to cool, it will be impossible to restore the markings, no matter how long you treat the surfaces with acid. The veining, on the other hand, produced by the mixture of metals never disappears, however much the steel may be heated. But if the piece of boulat, in which the veining has disappeared, be melted again, then, if certain conditions in the cooling of the ingot are observed, the veining appears again, though of a somewhat different design ; and in this manner it is possible to produce or annihilate the pattern several times. The investigations of Anosoff have clearly shown that the problem is solved in the purity of the steel, and he has succeeded, as is well known, in producing the very highest qualities of Eastern boulat. On a former occasion I spoke of the observations I had made on the ribbons of dead tint observable on the surfaces of steel guns in the lathe. By means of careful daily records in the forging of the gun ingots, I found that these tints appeared in the boundaries between the hot and the cold portions of the ingot being forged; that is to say, always at those points up to which the ingot was pushed into the furnace. The position and appearance of the strips of dead tint always coincided with the position and form of the limit of heating. If a spot so noted by me was afterwards reheated, then the ribbon of dead tint no longer appeared after turning in the lathe. Besides this, some of these ribbons would. disappear as a greater or less thickness of metal was turned off; others penetrated right through the mass of the gun, and never disu appeared.

It is further remarkable that although, at times, the transition from the beated to the cold portion of the ingot was so gradual thall it was impossible to assign any limit, yet the ribbon of dead tin developed by the turning of the surface of the gun; and correspond ing to the above ill-defined limit of heating, was so clearly marked that it was easy to trace its boundaries with a pencil on the surfac of the gun. It must be remarked also that the ribbon has only on well-defined margin, that which was turned towards the cold end 0 the ingot; the other margin is shaded off imperceptibly into th 
normal end of the steel. Wishing to investigate the effects of the steam hammer on the structure of steel, I heated a $4 \frac{1}{2}$ inch ingot to a bright red color, and subjected it to two heavy blows of a 5 -ton hammer, so that one-third the length was not touched at all, the second third was flattened to 3 in., and the last received two cross blows, under each of which there was a

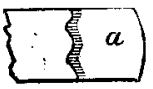
compression of at least $1 \frac{1}{2}$ in. The ingot was then left to cool in the open air, and on being broken it was found that the appearance of the structure of each of the three sections remained identical, not only to the naked eye, but to the most careful microscopical examinations.

I have also drawn attention to the circumstance that, on one occasion, when experimenting on the influence of the temperature to. which steel was heated, on its hardness in tempering, I ordered a: smith to heat a piece of steel to dull red, but he, by mistake, heated: it bright red. Wishing to rectify the error, I did not at once plunge. the steel into water, but let it first cool down to dull red, and then immersed it. Although the steel was of a quality capable of extreme hardness in tempering, the immersion not only did not make it hard, but actually made it sensibly softer. I have recalled the above circumstances, because in connection with many others, they induced me to investigate the influence of temperature on steel, and formed points of departure from my researches. Space will not allow of my describing my experiments in detail. I must content myself with stating the conclusions to which $I$ have arrived. If steel melted in a crucible is constantly kept in violent agitation while cooling, agitation violent enough to keep all its particles in motion, then the cold ingot produced will have a very finely crystallized structure; if, on the other hand, the melted steel is allowed to cool in perfect quiet, then the resulting casting will consist of large, well-developed crystals. The appearance of these crystals, and generally the tendency to crystallize under these circumstances, will depend on the purity of the steel. As I have already stated, the ultimate purity of the steel consists in that of the two component elements, iron and carbon, and that the best isteel is composed of only these two elementss: With reference to other elements, the presence of which is supposed to influence the quality of steel, it is impossible to avoid mentioning the opinion of Fremy; who considers nitrogen so essential, not only to the formation, but to the very existence of steel, that he has laid down the proposi- 
tion that "if nitrogen is taken away from steel it will cease to be steel"-Comptes Rendus, vol. lii., April, 1861; and the supporters of this theory, who go further, and affirm that steel is a union of iron with cyanogen, which can even be seen burning with a violent flame during the process of casting steel. However, up to the present time-1868-the most careful researches of Caron, Marchand, Biot, Bousingault, Rammelsberg, and others, have not confirmed the assertions of Fremy; for, on the one hand, nitrogen is found also in soft wrought iron and in cast iron, and on the other, the quantity of nitrogen found in steel is very variable, and bearing no fixed relation to the quantity of carbon; and furthermore, it exists in such small quantities as to be less than a tenth part of the carbon. For instance, Busengoll found 0.00057 part of nitrogen in cast steel, and .0 .00124 part in soft wrought iron.-Comptes Rendus, vol. lii., p. 1251. On another occasion, he found in Krupp steel 0.00022 part of nitrogen, and in soft wrought iron and in cast steel, 0.00007 part each.Comptes Rendus, vol. liii., p. 9.

With reference to the influence of different metals on the quality of steel, it is necessary to state that some of them communicate a particular color, some diminish the tendency to rust, and others displacing the carbon, enable the steel to acquire very great hardness in tempering, and so on; but the greater number of substances com. bined with steel, even in its most insignificant proportions, very considerably lower its quality. For example, the malleability of steel being in direct relation to the quantity of carbon contained in it, is materially lowered by the presence of foreign substances. Bessemer steel No. 1, containing 2 per cent. of carbon, is hardly malleableBoman, Das Bessemern in Schweden, 1864; whereas, according to Anosoff, pure steel retains its malleability with 3 per cent. of carbon, forming the hardest boulat. Speaking generally, all the efforts of metallurgists to obtain the highest qualities of steel should be directed to separating impurities from the raw materials, so that the produce of their operations should be a combination of iron and carbon; and all the specifics and nostrums forming the subjects of so-called secrets will be found to consist, in effect, not in the introduction of new materials, but in purifying the raw, and only, as a last expedient, driving out pernicious impurities by means of substances less harmful. It may as well be said that tungsten steel has not proved a dangerous rial to cabon stcel. Tho fact is that tungsten, when 
steel containing it is heated, gradually oxidizes, at first on the surface of the ingots, and then by degrees to the very centre, so that after a few heats the steel loses its peculiar qualities. This oxidation takes place even at ordinary temperatures.

As I have already stated, steel, cast and allowed to cool quietly, assumes a crystalline structure. If you heat such an ingot to a bright red heat, and allow it to cool without working it in any way, then on breaking the mass you will find that its structure has been altered. In order to explain the law regulating the change of structure produced by heating, I draw a line, on which, as on the scale of a thermometer, I shall mark certain points, corresponding to several determined temperatures.

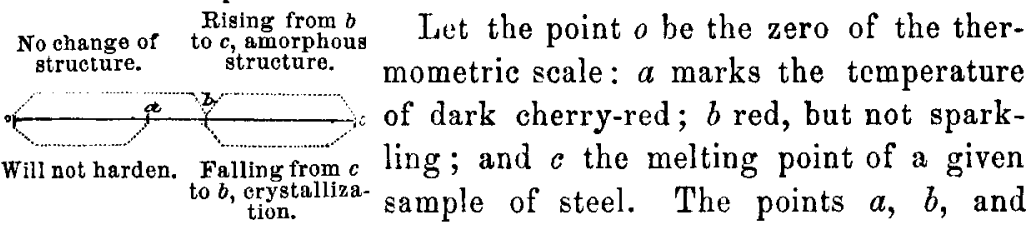
$c$ bave no permanent place on the scale, but vary with the quality of the steel (in pure steel this variation depends directly on the quantity of carbon contained); the harder the steel the nearer these points move to $o$, and the softer the steel the further off, and, speaking generally, with varying rates. The limits of these movements are sufficiently narrow, so that an inexperienced eye would hardly discern them. Not having suitable apparatus for measuring the temperatures, I have been compelled to denote them by the colors exhibited in heating, the various shades of which only an experienced eye can appreciate ; and it must be added, that the colors named have reference only to hard and medium qualities of steel; for in the very soft kinds, nearly approaching to wrought iron, the points $a$ and $b$ recede very far, so that, for example, in wrought iron the point $b$ corresponds to white heat.

The definition of the point $a$ is as follows:-Steel, however hard it may be, will not harden if heated to a temperature lower than $a$, however quickly it is cocled; on the contrary, it will get sensibly softer and more easily worked with the file. Not having time to enter into the explanation of this phenomenon, I will refer to the investigation of Jullien (Les affinites capillaires et les phénomènes de la trempe mis en présence, Paris, 1866) on tempering in general, from which he deduces the very probable conclusion that steel, in cooling 
from a red heat, appropriates a certain amount of latent heat, the quantity of which is directly dependent on the rate of cooling; so that the quicker the steel is cooled the greater quantity of latent heat it will contain; but if the rate of cooling diminishes below a certain limit, then the latent heat all escapes, and no hardening can take place. The actual hardening Jullien explains by the supposition that the carbon assumes an abnormal crystalline condition. I will add from myself that all this takes place only when steel is heated above the point marked $a$ on our scale. The definition of the point $b$ is that steel, heated to a lower temperature than $b$, does not change its structure, whether cooled quickly or slowly. This expression, however, must be taken conditionally, because steel, during long periods of time, and especially under the influence of shocks or vibrations, and at ordinary temperatures, but to a less extent than wrought iron changes from the finely granular to a coarse crystalline structure; and as regards the heated, and therefore softened, condition, and especially at temperatures approximating to that indicated by the point $b$, it is probable that with the greater facility of motion, the change of structure will take place more rapidly. In my own experiments I have kept pieces of steel at temperatures near to $b$ for about eight hours, but after cooling slowly in hot sand, I have been unable to detect any change of structure. As soon as the temperature has reached the point $b$, the substance of steel quickly passes from the granular (or, speaking generally, crystalline) condition to the amorphous (wax-like structure), which it retains up to its melting point, that is, to the point $c$. In this condition steel possesses the property of incompressibility, and, at the same time (with respect to the permanence of the amorphism), has an analogy to an exceedingly concentrated solution of a strongly crystalline salt. To make my meaning clearer, imagine a piece of crystallized alum put into a beaker and carefully heated. On attaining a certain determined temperature the piece of alum will appear as if damp, the separate crystals forming the mass will seem, as it were, to be sticking or clinging to each other, forming a mass on the point of melting, and which actually gradually becomes fluid, and forms a solution of the crystals of alum in their own water of crystallization. Now if this fluid mass is allowed to cool, it will again crystallize, and according to the conditions under which this cooling takes place we can obtain any quality of crystals, from the coarsest to grains so fine as to be scarcely per- 
ceptible to the naked eye. If the fluid is allowed to cool very slowly, and in perfect quiet, then large regular-shaped, well-developed crystals will be formed; but if, with the same gradual cooling, the liquid is kept in constant agitation (shaken up), the crystals will come out very small. Allowed to cool quietly but rapidly, the crystals will also be small; and, finally, the least favorable condition for crystallization is when the liquid cools rapidly, and is at the same time violently agitated. In a word, all depends upon the greater or less time and the greater or less freedom of motion the particles possess among themselves for collection into crystals; the first condition depends upon the rate of cooling, the second, upon quiet and the greater or less density (thickness) of the mass undergoing crystallization. The same changes take place in the structure of steel heat above the point $b$. The higher steel is heated the softer it becomes, the greater, therefore, is the liberty its particles possess to group themselves into crystals, if the quiet of the mass is not disturbed by extraneous forces; and the slower the temperature is suffered to fall to the point $b$ the more time they have for the purpose. At temperatures lower than $b$, as already stated, the structure of the mass does not alter. In this case the action of carbon on iron may be likened to that of water of crystallization on its salt; that is, it may be supposed that carbon at the temperature $b$ begins to dissolve iron just like the water of crystallization at certain temperatures commences to dissolve the solid substance of the salt. This hypothesis receives confirmation in the process of cementation, in which the iron must be heated to above a certain temperature or no effect will be produced, no matter how long the bars remain in contact with the carbon; it is very probable that the temperature at which carbon begins to be absorbed in cementation is very near to the point $b$.

The power of steel to become granular may be graphically illustrated thus :-On our scale of temperatures $0, a, b, c, a$ curved line rises from the point $b$, and the ordinates $y y$, \&c., of this curve represent the degree of development of the grains for the corresponding temperatures $x x x$,

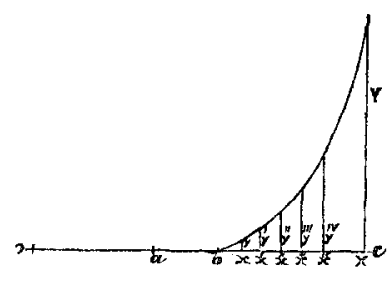
which become the abscissa, but necessarily under similar conditions of cooling from the several temperatures $x x$ to the temperature $b$. At some temperature $X$ lower than the melting point $C$, the ordinate 
$\mathrm{Y}$ becomes infinite, and an asymptote to the curve, the practical significance of which is apparent in the well known fact that steel will not endure a high welding heat, but falls to pieces in the fire; and the harder the steel the lower is the temperature at which this takes place, and, therefore, the nearer is the temperature $X$ to $o$, and the further from $\mathrm{C}$.

In manufacturing articles of steel we try to get them as much as possible of a fine grained structure, especially if strength or toughness is the first object sought. I say that it is better to obtain steel of a finely crystalline structure, because numerous experiments have demonstrated that the greater the preponderance of the crystalline formation, the larger and more regular the crystals are in a given piece of steel, the less resistance does it offer to fracture, the less tenacity does it possess, and, therefore, men connected practically with the working of steel recognize its qualities by the appearance of its fracture. If the fracture is fine-grained, they say the steel is well forged and consolidated; if it is coarse-grained, it is badly forged and of an open character.

Although we are in the habit of associating with the forging of steel an idea of increased density, yet, in reality, it appears that, in most cases, forging only changes the form of the steel, and, according to the relations between the force of the blows and the thickness of the piece of steel being worked, hinders crystallization of the mass to a greater or less degree, but does not increase its densityI am speaking only of forging above the temperature $b$, such as is general in working large ingots. The force of the blows is too small to vanquish that gigantic molecular force of heat that keeps the particles of steel at a definite distance one from the other. The problem of forging-at temperatures higher than $b$-consists in this, that while changing the form of the mass of steel, it should have no time to cool and crystallize quietly, but should be kept in the amorphous condition till such time as the temperature sinks below the point $b$, after which, if left to cool in quiet, the mass will no longer crystallize, but will possess great tenacity and homogeneity of structure, so that it will oppose in all its parts a uniform resistance to external forces, of course supposing the chemical composition of the mass throughout to be the same. But if the problem of forging was limited to the above conditions, it is easily seen, that working steel under the hammer might be dispensed with, and the required form given at once by 
casting in suitable moulds, and preventing crystallization by rapid cooling. In reality, however, things are very different. The diffculty of forging is aggravated by the circumstance that the cast ingots out of which guns, for example, have to be made, are full of pores, filled with gas, bubbles penetrating the interior as well as the surface of the mass, and also with scales and cracks due to contraction, so that, as the castings are delivered from the foundry, it would be impossible to make use of them. These bubbles and cracks must be squeezed or pressed together, and this can only be done by powerful mechanical means-by heavy forging. Simply unforged cast steel is neither less dense, nor less strong than steel of the same molecular structure, and forged at temperatures higher than b. To convince myself of this, I made a number of experiments, first on the density of the two kinds of steel, and found that in most cases forging had diminished the specific gravity; and, secondly, I found, that the tenacity of the cast steel was in nowise less than that of the forged, provided, as I said before, both have the same structure. To prove this, I took a cast ingot of coarse crystalline structure. I had it cut longitudinally into four parts. One of these parts was turned down in the lathe, and tested in the proving machine. The second piece was heated to bright red, and vigorously forged under a 3-ton hammer, the forging being stopped when the temperature fell to very nearly the point $b$; the specimen was then turned down, and also tested in the proving machine. The third piece was made redhot, very nearly the same temperature at which the forging of the second piece terminated, and was allowed to cool in the open air, without being forged. Having broken a small piece off this last specimen, I found that it had assumed a finely granular structure, very similar to that of the second forged specimen. The third sample was also turned down in the lathe and tested. The three specimens are now before you, and you may judge for yourselves what varieties of structure the self same piece of steel may be made to assume. The results of the experiments are given in the following table.

I must also remark that on the fractured surface of the third sample, as you may observe for yourselves, there is a spot of iron occupying about one-sixth of the area, and which was undoubtedly the cause of premature fracture, for the appearance of the fracture clearly shows that it began at that spot. In order to establish the propositions I have advanced, it will, of course, be necessary to institute a 
complete series of experiments.* As regards trials by bending and breaking under the hammer, an irmense number of experiments have convinced me of the correctness of my views.

1st. Unforged specimen

2d. Vigorously forged specimen...........

3d. Not forged, but made finely granular by heating...

\begin{tabular}{|c|c|c|c|}
\hline 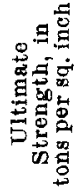 & 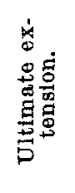 & 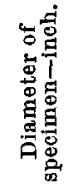 & $\begin{array}{l}\text { Dynamic resist- } \\
\text { ance per cubic } \\
\text { inch in inch tons. } \\
\text { Ulimate } \\
\text { Strength } \times 1 / 2 \\
\text { elongation. }\end{array}$ \\
\hline $\begin{array}{l}34 \cdot 8 \\
41 \cdot 5\end{array}$ & $\begin{array}{l}0.023 \\
0.053\end{array}$ & $\begin{array}{l}0.885 \\
0.85\end{array}$ & $\begin{array}{l}0.8 \\
1.1\end{array}$ \\
\hline $38 \cdot 7$ & $0 \cdot 166$ & 0.63 & 3.21 \\
\hline
\end{tabular}

[To be continued.]

\section{A MODERN ORGAN.*}

[From Nature, July 27th, 1876.]

It has been hitherto chiefly on the Continent of Europe that connoisseurs in the majestic tones of the king of instruments have had to seek for a grand organ. Though London, the mistress of the world for wealth and magnitude, has churches and chapels innumerable, and organs by hundreds, scarcely one is of sufficient importance or merit to attract the attention of a stranger. Church organs are, as a rule, small, and built without individuality or character of tone, and generally so placed in the building as to effectually mar in acoustical effect any special merit they might otherwise possess. Of the two or three instruments that have any pretensions to magnitude to which the public has access-at the Albert Hall and the Alexandra, and Crystal Palaces, no very lasting impression remains upon the audience beyond that of noise and a distressingly harsh volume of sound, utterly devoid of musical depth and grandeur of tone, and quite different from the pleasing reminiscences that dwell upon the memory from hearing some of their more musical Continental Rivals at Haar. lem, Freiburg, or Lucerne. To successfully construct a large organ is a work of exceeding difficulty, for not only does size greatly complicate the mechanical action, but the proper distribution and appor-

* 1875. Since the above was written, numerous experiments at the Abouchoff Works have fully demonstrated the truth of my views. 